\title{
Response of different citrus cultivars to citrus root nematode (Tylenchulus semipenetrans Cobb.)
}

\author{
Hafiz Muhammad Aatif ${ }^{1}$, Tauqeer Ahmad Yasir ${ }^{1 *}$, Chaudhary \\ Muhammad Shahid Hanif ${ }^{1}$, Allah Wasaya ${ }^{1}$, Muhammad Irfan Ullah², \\ Farooq Azhar ${ }^{3}$, Kazam Ali ${ }^{1}$ and Abdul Wahid Baloch ${ }^{4}$ \\ 1. College of Agriculture Bahauddin Zakariya University, Bahadur Sub-Campus Layyah-Pakistan \\ 2. Department of Entomology, University College of Agriculture, University of Sargodha-Pakistan \\ 3. Department of Forestry and Range Management, Bahauddin Zakariya University, Multan-Pakistan \\ 4. Department of Plant Breeding \& Genetics, Sindh Agriculture University, Tandojam-Pakistan \\ *Corresponding author's email: tayasir@yahoo.com
}

Citation

Hafiz Muhammad Aatif, Tauqeer Ahmad Yasir, Chaudhary Muhammad Shahid Hanif, Allah Wasaya, Muhammad Irfan Ullah, Farooq Azhar, Kazam Ali, Abdul Wahid Baloch. Response of different citrus cultivars to citrus root nematode (Tylenchulus semipenetrans Cobb.). Pure and Applied Biology. Vol. 7, Issue 1, pp349-355. http://dx.doi.org/10.19045/bspab.2018.70043

Received: 18/10/2017 Revised: 22/02/2018

Accepted: 24/02/2018

Online First: 07/03/2018

\section{Abstract}

Citrus is the most extensively produced fruit of world. Citrus root nematode (Tylenchulus semipenetrans Cobb.) is the predominant nematode present in citrus orchards of Pakistan. A greenhouse experiment was conducted to identify the accessions of nematodes in various citrus cultivars (Kinnow, Musambi, Shakri, Futrell's early and Blood oranges) for susceptibility, invasion, development and its effects on citrus growth. The results indicated that the maximum leaf losses $(31 \%)$ were recorded in Kinnow cultivar as compared to control due to infection with nematode. A similar trend was reported in all other cultivars. The results revealed that $T$. semipenetrans had lethal effects on the plant height. The maximum difference for plant height (25 $\mathrm{cm})$ was noticed in Musambi where $T$. semipenetrans treated plants showed an average plant height of $60 \mathrm{~cm}$; while in control it was $85 \mathrm{~cm}$. As for as the juveniles were concerned, the maximum number (3593) was noted for Futrell's early; the minimum (2956) juveniles were recorded in Shakri. Likewise, highest value (577) for females of T. semipenetrans was recorded in Futrell's early, while the lowest number (447) was counted in Shakri showing resistant and moderately resistant reaction to the tested nematode. The root weight of all citrus cultivars was statistically at par as compared to control. The maximum reduction (17.8\%) in shoot weight was noticed in Blood oranges, while all other cultivars also showed significant reduction in shoot weight as compared to control.

Keywords: Citrus slow decline; Citrus cultivars; Growth; Tylenchulus semipenetrans

\section{Introduction}

Citrus is being growing in more than one forty countries of the world [1] including Pakistan. However, the potential yield of citrus is $12-15$ tons per hectare, which is too less than the potential yield in Pakistan. There are various factors which are responsible for this low yield of citrus. 
Among these, the citrus root nematode (Tylenchulus semipenetrans) severely affects the citrus performance and yields, and is the major contributor of citrus decline in Punjab [2]. Javed et al., 2008 evaluated thirteen root stocks to identify genetic resistance against $T$. semipenetrans [3]. In another study, a differential resistance level was recorded in citrus cultivars against T. semipenetrans [4]. The most pragmatic option to control the citrus slow decline disease is the use of resistant cultivars. However, in Pakistan, very little efforts have been made to screen the citrus germplasm against the $T$. semipenetrans. Thus, the present study was aimed to screen the various citrus species against citrus slow decline disease through artificial inoculation. The specific objective of this study was to help the breeders and citrus growers to select the promising cultivars resistant to citrus slow decline disease, thus improving the citrus production.

\section{Materials and methods}

The experiment was conducted at the College of Agriculture, BZU, Bahadur sub campus, Layyah, Pakistan. The soil and root samples were collected from citrus orchards of Layyah. The fresh culture of $T$. semipenetrans ( $\mathrm{J} 2$ stage) was obtained from soil and roots by Whitehead and Hemming tray method [5]. The plants (30 months old), used in the study, were taken from Citrus Research Institute, Sargodha, and were kept in net house. The sterilized soil was used for all the pot experiments. The earthen pots (clay pots in the 15- to 18 inch-diameter) were filled with formalin sterilized soil [6]. The sterilization of sandy loam soil (72\% sand, $17 \%$ silt and $8 \%$ clay) was accomplished by applying formalin. The diluted formalin (1:320) was poured on the small heap of soil and was covered with polythene sheet to stop the fumes completely. Citrus cultivars (Kinnow, Musambi, Shakri, Futrell's early and Blood oranges) were transplanted into these pots. The pots were completely randomized, kept in the glass house and watering was done to avoid the drying of soil. After fifteen days, $2000 \pm 25$ freshly hatched juveniles in $15 \mathrm{ml}$ of water were added around the stem of plant of each pot by making holes [7] and then filled with oven sterilized soil to prevent the drying. Then, they were irrigated carefully. Over irrigation of the pots was avoided. The experiments were harvested after ninety days. J2s of T. semipenetrans were extracted using the Cobb's sieving and decanting technique with $0.7 \mathrm{~mm}$ and $45-75 \mu \mathrm{m}$ sieves. Mature females were extracted from a few grams of roots after $20 \mathrm{~s}$ maceration in a blender. Population of nematodes was estimated with the help of counting slide under inverted microscope. The untreated plants of each cultivar were served as control. The experiments were repeated twice to confirm the results. The association of inoculated nematodes was confirmed by reisolation as described by Koch's postulates. The data were recorded on growth parameters (fresh weight of shoot $(\mathrm{cm})$, fresh weight of root $(\mathrm{cm})$, root shoot ratio, number of leaves and plant height $(\mathrm{cm}$ and developmental parameters (number of females/gram of roots, number of $\mathrm{J} 2 \mathrm{~s} / \mathrm{g}$ of roots and number of $\mathrm{J} 2 \mathrm{~s} / 100 \mathrm{ml}$ of soil) were recorded following the standard procedure as described by Hutchinson and O'Bannon [8].

\section{Statistical analysis}

The collected data were analyzed by using statistical software 'statistics-8.1, and mean values were compared by Tuckey-HSD test at $5 \%$ significant level.

\section{Results and discussion}

The comparisons for the means of data regarding number of leaves noted in various citrus cultivars are given in Figure 1. The Figure depicted that all the treatments of citrus species were significantly different from their respective control treatments. The maximum numbers of leaves (80) were counted in the control treatment of Kinnow; 
while treatment of this variety with Tylenchulus semipenetrans reduced the number of leaves to 55. The Shakri produced the minimum number of leaves i.e. 31 and 42 in $T$. semipenetrans treatment and control treatment respectively. The trend for the number of leaves in $T$. Semipenetrans inoculated cultivars was as following: Kinnow (55) > Musambi (42) > Blood oranges (39) > Futrell's early (37) > Shakri (31) (Figure 1).

\section{겨 T. Semipenitras $\square$ control}

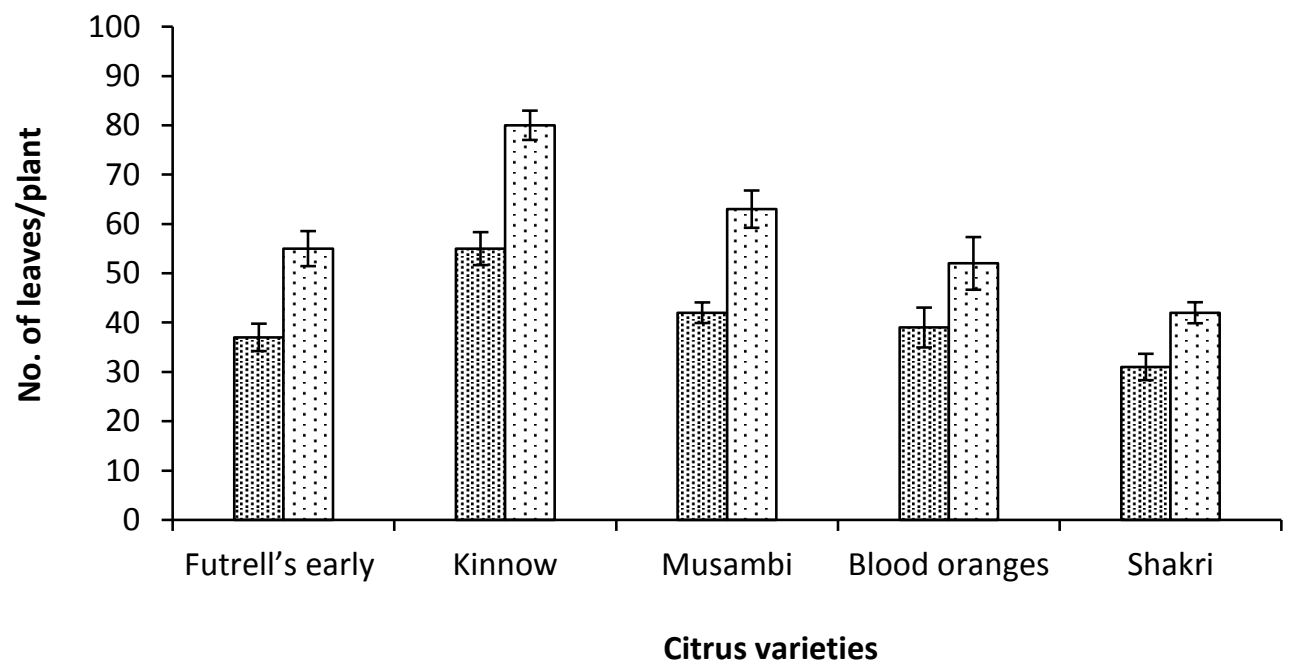

Figure 1. Mean comparisons for number of leaves per plants by the action of nematode $T$. semipenetrans in the various citrus cultivars

Data packed in (Figure 2) is showing the plant height of T. Semipenetrans treated and control treatment of citrus cultivars. The results evidenced that the nematode ( $T$. semipenetrans) had lethal effects on the plant height. The plant height of all the citrus cultivars was significantly stunted as compared to control treatment. The maximum difference for plant height $(25 \mathrm{~cm})$ was noticed in Musambi where $T$. semipenetrans treated plant showed $60 \mathrm{~cm}$ height, while in control it was $85 \mathrm{~cm}$. In all other treatments almost same difference for plant height were observed between control and treated experimental unit. The results also showed minimum plant height $(49 \mathrm{~cm})$ in Futrell's Early and maximum $(67 \mathrm{~cm})$ in
Blood oranges. Other two nematode treated plants, Kinnow and Shakri produced an average plant height of $54 \mathrm{~cm}$ and $59 \mathrm{~cm}$ height, respectively (Figure 2).

The high numbers of juveniles in each plant root system were counted in various citrus cultivars inoculated with $T$. semipenetrans, while no juvenile was reported in controlled plants. Comparisons of mean for numbers of juveniles per plant root system (Figure 3) indicated that maximum number (3593) was noted in Futrell's early while minimum (2956) was recorded in Shakri. In Kinnow, Musambi and Blood oranges, the counted number of juveniles was 3393, 3272 and 3144 respectively (Figure 3 ). 


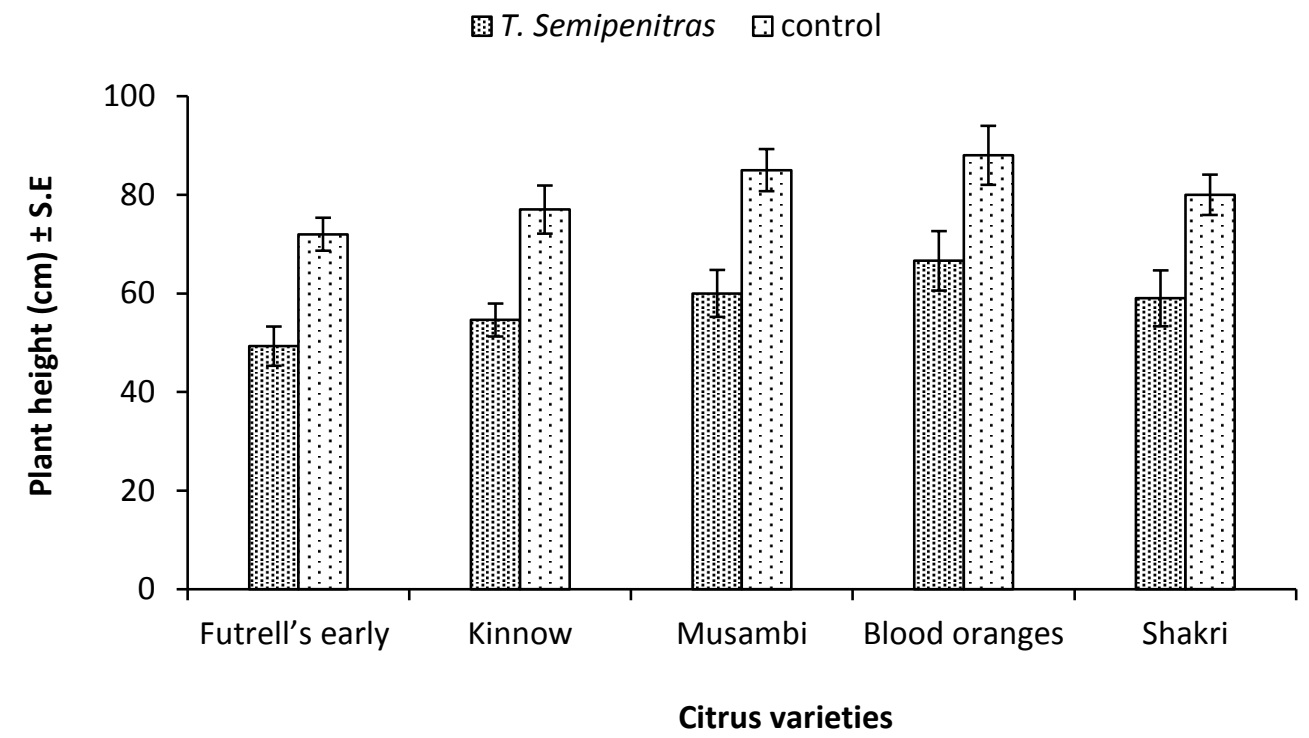

Figure 2. Mean comparisons for plant height by the action of nematode $T$. semipenetrans in the various citrus cultivars.

\section{国 T. Semipenitras $\square$ control}

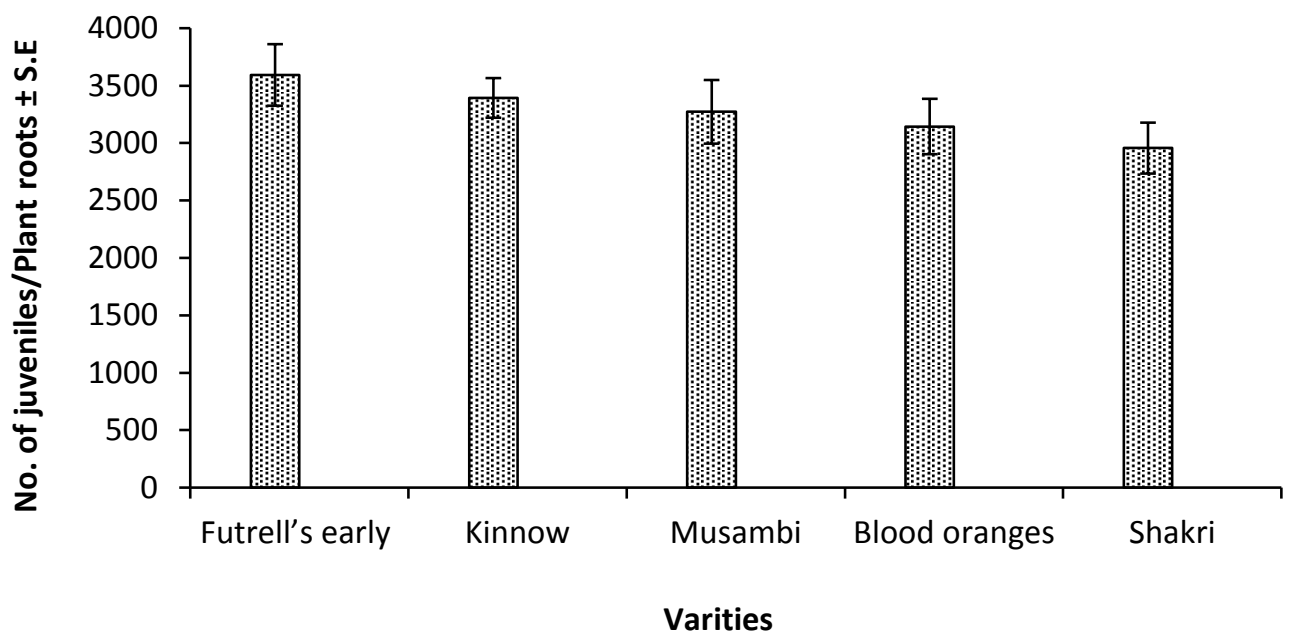

Figure 3. Mean comparisons for the number of juveniles per plant root system by the action of nematode $T$. semipenetrans in the various citrus cultivars

$T$. semipenetrans females in tested citrus cultivars were also counted in $T$. semipenetrans inoculated plants and control cultivars. The data recorded for the number of females of $T$. semipenetrans from three replicates is presented in (Figure 4). In control treatment, no female was reported; while in $T$. semipenetrans inoculated plants, large numbers of females were counted. The highest value (577) for females of $T$. semipenetrans was recorded in Futrell's Early, while the lowest number (447) was counted in Shakri. In other three plants (Musambi, Kinnow and Blood oranges), 571, 519 and 477 females of $T$. semipenetrans were noticed respectively (Figurer 4). 


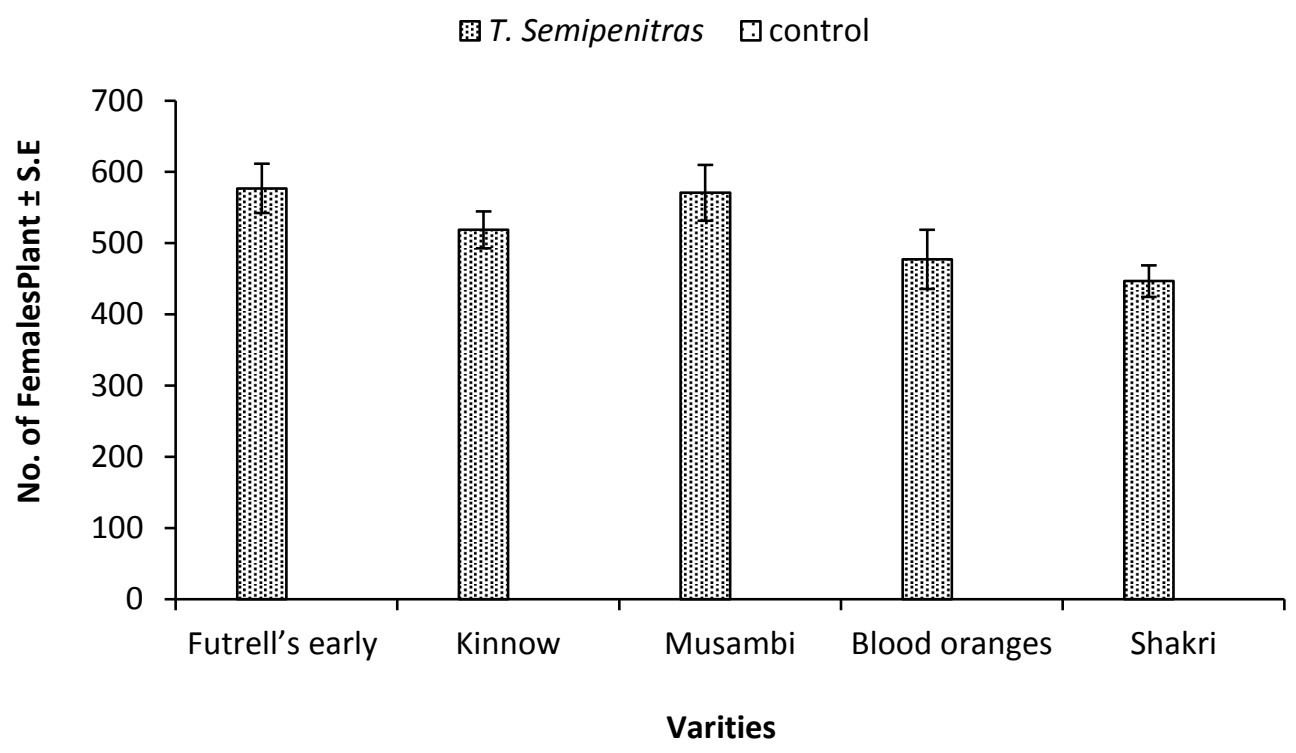

Figure 4. Mean comparisons for the number of females (T. semipenetrans) noted in various citrus cultivars

The root weight of all citrus cultivars was statistically at par with each other except control treatments. There were only slight differences among fresh weight of roots for all $T$. semipenetrans treated citrus cultivars. For treatments, the maximum fresh root weight $(5.66 \mathrm{~g})$ was noted in Blood oranges followed by Musambi (5.4 g), Kinnow (5.4 g), Shakri (5.4 g) and Futrell's early (5.3 g). In control treatments, maximum $(7.8 \mathrm{~g})$ and minimum values $(6.8 \mathrm{~g})$ were checked in Shakri and Futrell's early for fresh root, respectively (Figure 5).

7. Semipenitras $\square$ control

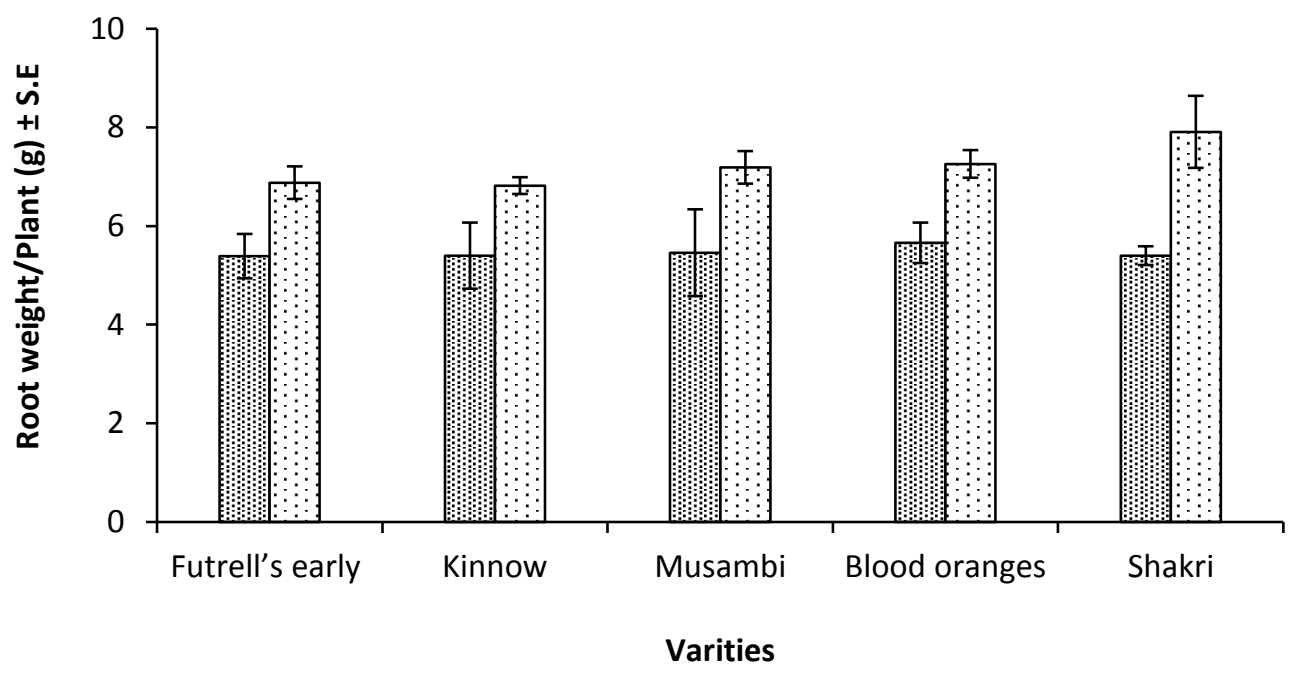

Figure 5. Mean comparisons for fresh root weight (g) per plant by the action of $T$. semipenetrans in the various citrus cultivars 
The data shown in Figure 6 specified the plant shoot weight for various treated and controlled citrus cultivars. The nematode ( $T$. semipenetrans) had adverse effects on the shoot weight of the plants. Shoot weight of all citrus cultivars was significantly reduced as compared to control treatments. The maximum value for shoot weight $(17.4 \mathrm{~g})$ was noticed in control of Blood oranges, whereas T. semipenetrans treated Blood oranges plant had a $14.3 \mathrm{~g}$ shoot weight. In remaining four citrus cultivars (Futrell's Early, Kinnow, Musambi and Shakri), 12.9g, $13.48 \mathrm{~g}, 13.90 \mathrm{~g} 14.20 \mathrm{~g}$ and $16.0 \mathrm{~g}, 16.4 \mathrm{~g}$, $17.3 \mathrm{~g}, 17.1 \mathrm{~g}$ shoot weight was confirmed in $T$. semipenetrans treated and control treatments, respectively (Figure 6).

\section{영 T. Semipenitras $\square$ control}

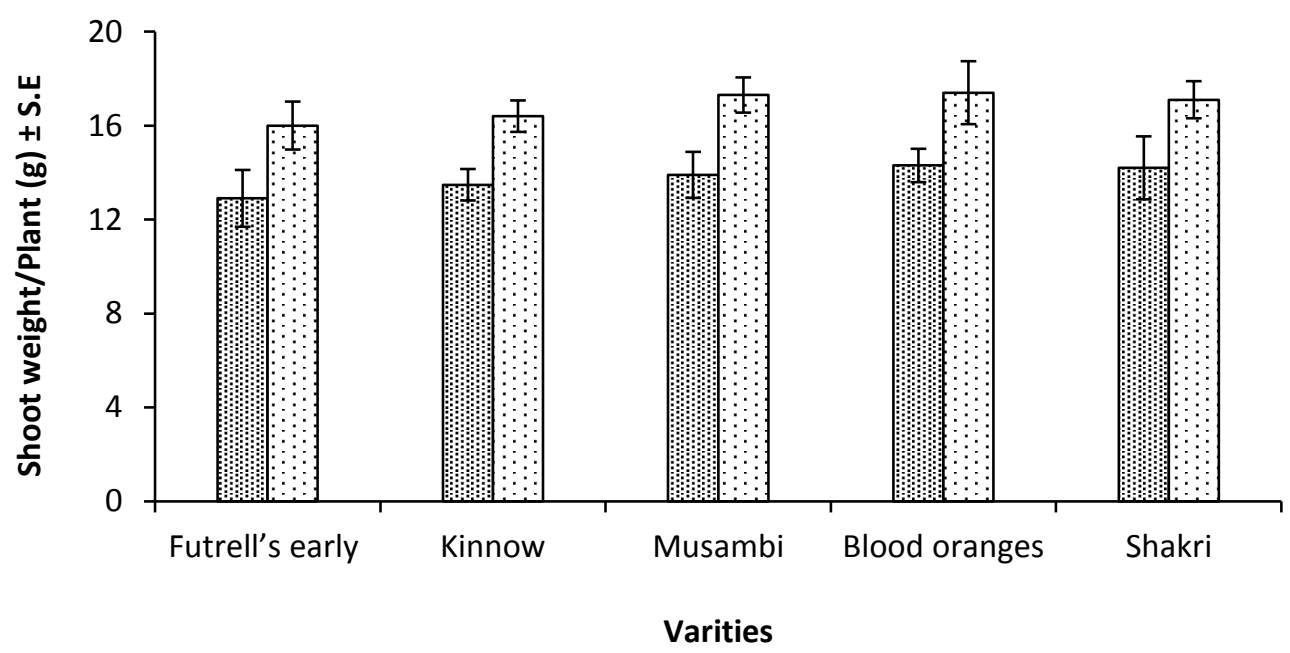

Figure 6. Mean comparisons for shoot weight $(\mathrm{mg})$ per plant by the action of $T$. semipenetrans in the various citrus cultivars

Indeed, the $T$. semipenetrans has been the target nematode in screening tests of citrus and citrus relatives, in California and India [9, 10]. Most citrus rootstocks used commercially are attacked by the citrus nematode, T. semipenetrans. It was found that due to infection of nematode, the maximum leaf losses $(31 \%)$ were recorded in Kinnow cultivar as compared to control. The results revealed that nematode ( $T$. semipenetrans) had lethal effects on the plant height. Maximum difference for plant height $(25 \mathrm{~cm})$ was noticed in Musambi where $T$. semipenetrans treated plants showed $60 \mathrm{~cm}$ height while in control it was $85 \mathrm{~cm}$. As for as the juveniles were concerned, Shakri showing resistant and moderately resistant reaction to the test nematode. Root weight of all citrus cultivars was statistically at par as compared to control. Maximum reduction (17.8\%) in shoot weight was noticed in Blood oranges, while all other cultivars also showed significant reduction in shoot weight as compared to control. It has been estimated that $70-80 \%$ of citrus trees throughout the world are infested with $T$. semipenetrans. The results revealed that all the cultivars are susceptible against citrus slow decline disease. As for as the nematode developmental parameters were concern, the least susceptibility was observed in Shakri, Kinnow and Musambi cultivars while Futrell's Early was the most susceptible to the nematode [11]. Indeed, $T$. semipenetrans is a specific plant parasitic nematode. If, we plant highly resistant rootstocks, it will result 
in the development of new nematode biotypes due to selection pressure which may survive on the resistant rootstock [12]. In citrus species, a host response to pathogens has been observed which provide a selective mechanism to resist the infection $[13,14]$. The measurements of the extent of growth parameters and developmental parameters between citrus cultivars could be a valuable tool in distinguishing levels of susceptibility and resistance against citrus slow decline disease.

\section{Conclusions}

This study indicated that the Kinnow, Shakri and Musambi were the most tolerable, and resistant cultivars to $T$. semipenetrans. Future studies are needed to determine the mechanisms involved in the identification to the gene for T. semipenetrans resistance. It is also needed to identify the symptoms on nursery livestock to indicate the presence to avoid its distribution the citrusgrowing areas of the country.

\section{Author's contributions}

Conceived and designed the experiments: HM Aatif, TA Yasir \& A Wasaya, Performed the experiments: F Azhar, MI Ullah \& K Ali, Analyzed the data: AW Baloch \& A Wasaya, Contributed reagents/ materials/ analysis tools: HM Aatif \& TA Yasir, Wrote the paper: HM Aatif \& K Ali.

\section{References}

1. Liu C, Cheng Y, Zhang H, Deng X, Chen F \& Xu J (2012). Volatile constituents of wild citrus Mangshanyegan (Citrus nobilis Lauriro) peel oil. J Agric. Food Chem 60: 2617-2628.

2. Anwar SA \& Sarwar M (1981). Nematodes associated with citrus roots and rhizosphere in the Punjab. J Agric Res 19: 141-146.

3. Javed N, Javed M, Ilyas MB, Khan MM \& Inam-Ul-Haq.M (2008). Reaction of various citrus root stocks (germplasm) against citrus root nematode (Tylenchulus semipenetrans Cobb.). Pak J Bot 40: 2693 2696.

4. Sunartoi T \& Ntasasmita S (2011). Resistance level of some citrus cultivars to the citrus nematode (Tylenchulus semipenetrans Cobb.) in west Java, Indonesia. Lucrari Ştiinţifice 54: 11-14.

5. Whitehead AG \& Hemming JR (1965). A Comparison of Some Quantitative Methods Extracting Small Vermiform Nematodes from the Soil. Ann Appl Biol 55: 25-38.

6. Aatif HM, Javed N, Khan SA, Ahmed S \& Raheel M (2015). Virulence of entomopathogenic nematodes against Meloidogyne incognita (Kofoid and White, 1919) Chitwood (1949) for invasion, development and reproduction at different application times in brinjal roots. Int J Agric Biol ISSN print: $1560-8530$.

7. Campos HD \& Campos VP (2005). Studies on inoculum, inoculation and extraction of root-knot nematodes, Meloidogyne javinaca. Nematol Brasil 29(1):75-82.

8. Hutchison DJ \& D'Bannon JH (1972). Evaluating the reaction of citrus selections to Tylenchulus semipenetrans. Plant Dis Rep 56: 747-751

9. Niles RK, Freckman DW \& Roose ML (1995). Use of trifoliate orange as a comparative standard for assessing the resistance of citrus rootstocks to citrus nematode. Plant Dis 79: 813-818.

10. Reddy PP \& Agarwal PK (1987). Resistance in citrus rootstocks to the citrus nematode Tylenchulus semipenetrans. Ind J Hort 44: 111-114.

11. Baines RC, Miyakawa T, Cameron JW \& Small RH (1969). Infectivity of two biotypes of the citrus nematode on citrus and on some other hosts. J Nematol 1: 150-159.

12. Lucas V, Sorribas FJ \& Alcaide A (2000). Resistance of hybrid citrus rootstocks to a Mediterranean biotype of Tylenchulus semipenetrans Cobb. Hort Sci 35: 269-273.

13. Kaplan DT (1981). Characterization of citrus rootstock responses to Tylenchulus semipenetrans (Cobb). J Nematol 13: 492498.

14. Doucet ME \& Ponce de leon EL. (1992). Tylenchulus semipenetrans Cobb, 1913 (Nemata: Tylenchida) y su asociation con Citrus auranatium L. y Citrus reshni Hort. Ex Tan Agric Scientia 9: 113-116. 